International Journal of Linguistics, Literature and Translation

ISSN: 2617-0299 (Online); ISSN: 2708-0099 (Print)

DOI: 10.32996/ijltt

Journal Homepage: www.al-kindipublisher.com/index.php/ijltt

\title{
Using Instructional Games in Teaching Grammar: The Case of Moroccan EFL Common Core Students
}

\author{
El Hamydy El Mehdi $\mathbf{8}$ (D) \\ Doctoral student, English department, Faculty of Languages, Letters \& Arts, Ibn Tofail University, Kenitra 14000, Morocco \\ \Corresponding Author: El Hamydy El Mehdi, E-mail: elmehdi.elhamydy@uit.ac.ma
}

ARTICLE INFORMATION ABSTRACT

Received: August 17, 2021

Accepted: September 23, 2021

Volume: 4

Issue: 9

DOI: $10.32996 / i j l t .2021 .4 .9 .22$

\section{KEYWORDS}

Board games, grammar, instructional games, tic-tac toe.
This paper reports on a quasi-experimental study that examines the use of instructional games in teaching grammar, and in particular, it explores the effect of tic-tac toe and board game on the present continuous and present simple. The study was conducted among $60(\mathrm{~N}=60)$ Moroccan $\mathrm{EFL}$ common core students from two different high schools in Casablanca. All the participants took a pre-test prior to instruction and a post-test immediately after the training, which lasted three sessions. The experimental group $(n=30)$ were instructed using instructional games, mainly tictac toe and board game. However, the control group $(n=30)$ received no treatment. The experimental group was also given a feedback questionnaire at the end of the training. The data sets were submitted to SPSS, using the Independent T-test. The findings indicated that all the participants were equal in the pre-test. Nonetheless, the experimental group outscored the control group in the post test. The results of the feedback questionnaire were also in line with the whole-results of the study. It can be concluded that the tic-tac toe and board game had a momentous effect on the subjects' understanding of the present simple and present continuous.

\section{Introduction}

Games have recently been perceived as a potential learning medium of instruction, as they provide a great deal of knowledge, motivation, fun, entertainment, engagement and involvement in the field of education. Research has revealed that games have become a ubiquitous part of all kids' and teenagers' lives, with 97\% playing approximately two hours per day in the USA (Granic et al., 2013). These statistics are almost the same in other countries, such as the UK, where $60 \%$ of the population whose age ranges between 6 to 65 years are gamers (Pratchett, 2005), or Germany, where $72 \%$ of boys and 52\% of girls play at least one hour per day (Moller \& Krahé, 2009). Despite the fact that previous research on the effects of games on violence, addiction and depression has attained a lot of attention (e.g. Anderson et al., 2010; Ferguson, 2013; Lemola et al., 2011), we believe that a more balanced perspective is necessary-one that considers not only the negative impacts but also the advantages of using games in teaching and learning. In this respect, learning grammar through instructional games has recently gained a lot of attention. Research has revealed that instructional games are beneficial in grammar acquisition, for they foster learners' ability to recall sentence structure, rules, and patterns, etc., encourage learners' participation and interaction, enhance their conceptual, analytical and communicative skills, and help teachers to create a meaningful context for learning to take place (Alemi, 2010; Donmus, 2010).

The current study has a quasi-experimental design, in which 60 Moroccan EFL common core students participated. These participants took a pre-test prior to instruction and a post-test immediately after the training. The experimental group were instructed grammar using instructional games, whereas the control group received no special treatment. Nonetheless, the design of this study involves some limitations (see Section 5.2). In addition to this introduction, this paper consists of three main chapters. The first one is primarily concerned with the theoretical framework upon which the current study is based. The second chapter describes the main steps followed throughout the conducting of the intervention. In this regard, it consists of a detailed

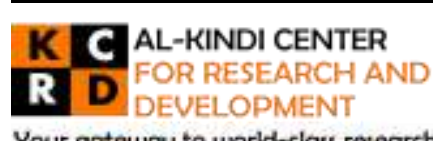

Your gateway to world-class research

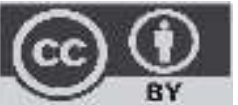

Published by Al-Kindi Center for Research and Development, London, United Kingdom. Copyright (c) the author(s). This open access article is distributed under a Creative Commons Attribution (CC-BY) 4.0 license 
description of the design, participants, instruments, procedure, piloting, and administration of the pre-test, post-test along with scoring and data analysis. The last chapter highlights the findings obtained from the administration of the pre-test, and posttest, using both descriptive and inferential statistics. It also discusses the results of the present study, in relation to prior research. It ends with listing some pedagogical implications and suggesting some practical recommendations for future research. This paper aims to investigate the use of instructional games in the Moroccan EFL context. In particular, it examines the effect of tictac toe and board games on teaching and learning the present simple and present continuous. In other words, it seeks to understand the extent to which the training would help the experimental group to outscore the control group in the post test. In order to meet these objectives, the following research questions have been formulated:

1- Will the experimental group outperform the control group in the post-test?

2- How can we account for the difference if there is any?

\section{Literature Review}

This study addresses the use of instructional games in teaching grammar. It sheds light on the issue of instructional games within the field of education and language learning classrooms. Grammar is a mere description of how a language functions. It describes a lot of things. For example, it tells us the order in which sentence constituents must be arranged. It further explains the way the various types of words function - the work that a noun does differ from that of an adjective. It also explains the way words change their category according to the way they are used. A lot of people use the term 'grammar' to mean the rules of language, yet grammar has a more specific meaning. Grammar is concerned with the structure of language - with the words, phrases, and clauses that are considered as the building blocks of sentences (Warriner, 2008). Second, the term 'game' is ambiguous, as it is intertwined with multiple categories, including but not limited to, simulations, computer games, video games, and serious games. These terms have created confusion among researchers, some of whom used the same terms interchangeably to refer to the same thing (Hainey, 2013). Since the term 'games' is confusing, researchers have provided a set of definitions to account for this term. Some of them suggest that games are rule-governed and outcome-oriented because players often attempt to attain a goal at the end of the game (Juul, 2005; cited in Hainey, 2013, p.4). Overall, there is a wide category of games under the 'conceptualization of game'. This study focuses on the following instructional games: tic-tac-toe and board game. For the purpose of this paper, an instructional game is: operated in a formal setting (e.g. classroom), developed for instructional purposes (e.g. learning, teaching ...); and involves three main components: players who take part in the game (e.g. for entertainment, enjoyment or amusement), rules which dictate the limits and constraints of the game, and goals which give arise to competition, rivalry, and challenge among players (Prensky, 2001).

English language teaching has witnessed a shift from a teacher-centred approach to a learner-centred approach, in which students are encouraged to assume more responsibility for their own learning. This change is reflected in the teaching methods and approaches adopted by teachers in the classroom. In this respect, there has been a long-standing debate about the teaching of grammar, and teachers have been using different methods and approaches, as different as Grammar Translation Method (GTM), Audio-Lingual Method (ALM), Natural Approach, Total Physical Response, Communicative Language Teaching, TaskBased Approach, Standards Based Approach, Eclecticism, etc.) to teach grammar over time. For instance, In GTM, the focus has been on language structure or form, in the sense that learners are explicitly given the rules and are asked to apply them on a variety of exercises. in the ALM, pupils are asked to listen and repeat the correct grammatical structure, so that they could memorize it without making any mistake. In the communicative approach, the emphasis is not on language accuracy but on fluency, in which students are encouraged to use the language communicatively.

A large body of empirical research has examined the major effect of instructional games on teaching grammar. In particular, research has shown that instructional games improve students' knowledge of syntactic and grammatical forms (e.g. the form of simple present and present continuous) (Miller \& Hegelheimer, 2006; Anderson et al., 2010; Squire, 2007; Gee, 2007). For example, Miller and Hegelheimer (2006) examined the usefulness of instructional games in language learning classrooms and reported significant findings. Anderson et al. (2010) also conducted an experimental study on the effectiveness of digital games in language learning classrooms, the results of which revealed statistically significant differences between the experimental and the control group. Besides, Squire (2007) argued that instructional games had attracted significant attention from teachers as a medium of learning. In the same vein, Gee (2007) argued that although games are full of fun and entertainment, research has proven their usefulness in teaching and learning. In principle, games are definitely one of the crucial means of teaching grammar, since they involve students in the learning process. The use of games in the classroom provides students with intrinsic motivation to master the target structure, encouraging them to understand how a particular form is used (Vernon, 2006). This section has presented the theoretical framework upon which this study is based. 


\section{Methodology}

This part provides a detailed description of the methodology adopted to meet the research objectives, and thus information relative to the design, the participants, the instruments, and the procedure are presented in detail.

\subsection{Research Design}

The current paper falls within the umbrella term of the quasi-experimental design; since it involves an experiment (Table1). It is assumed that there is a causal relationship between the independent variable (instructional games) and the dependent variable (grammar). In other words, it is hypothesized that students' performances in grammar activities are subject to the treatment (instructional games). However, confounding variables other than the treatment variable may play a major role in the observed variations. This being the case, the participants were randomly assigned either to the experimental or the control group.

Table1: The design of the study

\subsection{Participants}

\subsubsection{Subjects}

The training was conducted in two public high schools located in Casablanca, Morocco; during the last three weeks of October 2019. A cohort of 60 subjects took part in the training. All the participants share the same level of education (common core) and the same stream (sciences) with an age average of 14 years old. We also made sure that the subjects were not taking extra courses in English during the training, and that they had not participated in the same experiment. These factors suggested they had the same degree of homogeneity and congruity, and therefore they were all equal at the beginning of the training. In addition, the experimental subjects were taught using instructional games, whereas those in the control group did not receive any special treatment. Nonetheless, participants in both groups received the same amount of material.

\subsubsection{Instructors}

Two novice teachers took part in this study. Each teacher taught their own classes, which facilitated communication and interaction, and made the students more responsive to the training.

\subsubsection{The Choice of the sample:}

The choice of this sample is driven by the fact that the participants' level of English is adequate for the purpose of the study-the subjects share the same level of education, which is an important factor per se.

\subsection{The instruments}

Two research instruments were used to conduct this experiment. The first instrument was a one-page feedback questionnaire given to the experimental group at the end of the training. Second, pre-test and post-test grammar questions served as the second instrument in this paper.

\subsubsection{Description of the feedback questionnaire}

The feedback questionnaire included different questions which targeted the participants' attitudes towards and evaluation of instructional games (Appendix-V). The subjects were given open ended questions (with enough space) to express their opinions freely concerning the training they received. The first two questions were closely interrelated, for they were intended to know subjects' opinions about instructional games and whether they benefited from those strategies or not. The third question was meant to see whether subjects were by that time using some other techniques that they were unaware of before the training. The fourth question was included to see whether the participants would use these instructional games in their future and whether they would extrapolate them to other courses when grammar is involved. Question five examined the extent to which subjects had internalized the instructional games they had been exposed to during the training sessions. The last question was somehow identical to the first and second questions, in a way that it targeted participants' attitudes towards the instruction.

\subsubsection{The pre-test and the post-test}

Given that the current study did not involve random selection, a pre-test was administered to explore the level and the homogeneity of the students before the outset of the intervention. The pre-test was also necessary for comparing students' scores (both groups), in order to see whether or not the subjects had made progress in the post-test.

\subsubsection{Piloting of the tests}

The reason behind piloting was to anticipate the issues we would encounter on the day of running the tests, such as the timing, construction of the questions, linguistic difficulty, etc. so that the tests would fit the aim of the training and the target 
population. Every teacher tested the pre-test and post-test on a small group of common core students in the schools where they teach. The piloting was conducted in the circumstances similar to those in the real intervention. Modifications involved the three tasks.

\subsection{Data collection procedure}

This study is constituted of four different stages: the preparatory stage, the pretest, the training and the post test.

\subsubsection{The preparatory stage}

Before the training, the two teacher trainees and their supervisor met to discuss the content of the study and to agree on the design, rationale, and implementations. This meeting was so helpful that it opened a room for improvement, modification, and remediation that were suggested in advance.

\subsubsection{Administration of the pre-test}

In the absence of random selection, a pre-test was administered to explore the level and the homogeneity of the subjects. They were told by their respective instructors (in the presence of the researcher) that the pre-test was part of a study, in the form of an experiment in which they would participate. The instructor further informed the participants of the study requirements, along with the amount of time it would last. They were also assured that their scores would be kept confidential and would be utilized for the aim of the intervention.

\subsubsection{Training sessions}

The experimental group received three sessions, as a treatment, in which they were instructed the present simple and the present continuous using two instructional games: tic-tac toe and board game.

\subsubsection{The experimental group}

This experiment involved one experimental group of 30 subjects. This intact group received three sessions, in which they were exposed to the treatment: tic-tac toe and board game. During the first session, we had an informal discussion with the subjects to discuss the obstacles that hindered their understanding of grammar. Interestingly, students seemed to have appreciated our utmost care as far as their grammar comprehension is concerned. It was also an opportunity for some low achievers to express their views and participate in the general class discussion. The thing is that most students still have difficulties with the present simple and the present continuous, and thus it was the right time for us to introduce instructional games to boost their grammar. Albeit students were unacquainted with the discussion about instructional games and their importance in learning, they were all ears, showing much interest in the way we explained the subject matter. In principle, students were introduced to the instructional games the training would cover.

During the second session, we explained the instructions of each game in detail. Students seemed to have understood the implementation of the games in the previous session, and therefore it was easy to ask them to practice the games at play. For the tic-tac toe, we printed out flashcards with daily activities (a girl cooking dinner, a boy jogging, a woman brushing her hair, etc.), took them together making a large tic-tac toe board and put it on the board. We divided the class into two teams, team $X$ and team $O$. In turns, each team had to choose a square and use the present continuous to describe the activity in that square. When the students answer correctly, they put their respective $\mathrm{X}$ or $\mathrm{O}$ in the box and if they do not get the right answer, the other team try to find out the correct answer. Students played this game 3 times. We also kept scores to create a competitive and a more dynamic classroom. As for the board game activity used to teach the present simple, it aimed at enabling students to use the present simple communicatively, in a way that students developed a short conversation after each answer. For instance, student A would ask student B "How often do you play football?" and the latter would answer "I play football every weekend." We designed the board game activity in A3 size. We divided the students into groups of 5 and we ensured to explain in detail the instructions of the game. We gave each group a board game, a dice and indicators. To play the game, student threw the dice and moved forward that number of square and answered the question (e.g. How often do you go shopping?). When the student got it right, she or he threw the dice again and answer the question, and when he/she got it wrong, she/he had to step back and another player took his or her turn, etc. Students took turns until one student reached FINISH and that student was the winner. The same procedures were used during the third session. It is worth noting that students 'performances have improved in the third session, compared to the previous sessions. Most students have so far understood how each game is played, and they rarely ask their teacher for help.

\subsubsection{The control group}

The experiment also involved one control group of 30 subjects. This intact group received three sessions, in which they were taught the present simple and continuous traditionally. Students were informed that they would participate in an experiment. However, the participants were not given any clue regarding the nature of the data the researcher attempts to elicit. Yet, the procedures were made clear for them. 


\subsubsection{Administration of the post-test}

At the completion of the training, participants in both groups were given the posttest, which was roughly similar to the pretest in terms of structure, tasks and difficulty.

\subsection{Soring and data analysis}

This section describes the components of the tests and how these tests were scored. It also explains how the data sets were submitted to SPSS.

\subsubsection{Scoring}

Each test had a sum total score of twenty. The test consists of three tasks, each of which was allotted a score based on its weighting. This being the case, the first task was given six points. The second task was also given six points. However, the last task was worth eight points, not only because it combined both tenses, but also there were more blanks to fill in compared to the previous tasks. The reason why the test components received different weightings can be justified on the ground of the validity of each task and time allocation that each task would take.

\subsubsection{Data analysis}

The data were submitted to analysis using the SPSS. Given that the current data were continuous, descriptive statistics were used to measure the central tendency. Since the means obtained from the data were insufficient to make cause-effect claims, we ran inferential statistics. The software package IBM SPSS statistics version 20.0 was used in data analysis. An independent samples ttest was used to check if there was a significant difference between pre-test of both groups. This test allows for the comparison between the performances of both groups on the presence or absence of instructional games. However, the qualitative data was not subject to statistical tests, and it was collected by means of the administration of the feedback questionnaire. In sum, this part has described the methodology used to conduct the present experimental study.

\section{Results and Discussion}

In order to answer the research questions, we need to run a thorough analysis of both descriptive and inferential statistics.

\subsection{Descriptive statistics}

The descriptive statistics for the pre-test and the post-test, including group means and standard deviations for each group, appear in Table2, and the group means are plotted on the graph in Figure1. Accordingly, the analysis of descriptive statistics shows that both groups scored the same at the beginning of the training (pre-test). The pre-test means scores (12.60 for the ex. group and 12.89 for the control group) suggest that all the participants had the same level of understanding grammar (i.e. the present simple and the present continuous) at first. The means of the post-test, however, reveal that the experimental group outperformed the control group (with a - 03.67 gain score). Nevertheless, it is worthy to note that descriptive statistics only indicate a numerical difference in the groups' mean scores (see Table2 and Figure1). It remains, then, to run inferential statistics to confirm if these numerical differences are statistically significant.

Table2: numerical summary of the data set

\begin{tabular}{|l|l|l|l|l|l|}
\hline Group & \multirow{2}{*}{ N } & \multicolumn{2}{|c|}{ Pre-test } & \multicolumn{2}{c|}{ Post test } \\
\cline { 3 - 6 } & & Mean & $\begin{array}{l}\text { Standard } \\
\text { Deviation }\end{array}$ & Mean & $\begin{array}{l}\text { Standard } \\
\text { Deviation }\end{array}$ \\
\hline Expe Group & 30 & 12.60 & .723 & 16.73 & .739 \\
\hline Con Group & 30 & 12.89 & .747 & 13.06 & .868 \\
\hline
\end{tabular}

Figure1: Boxplots of the pre-test and post-test of both groups

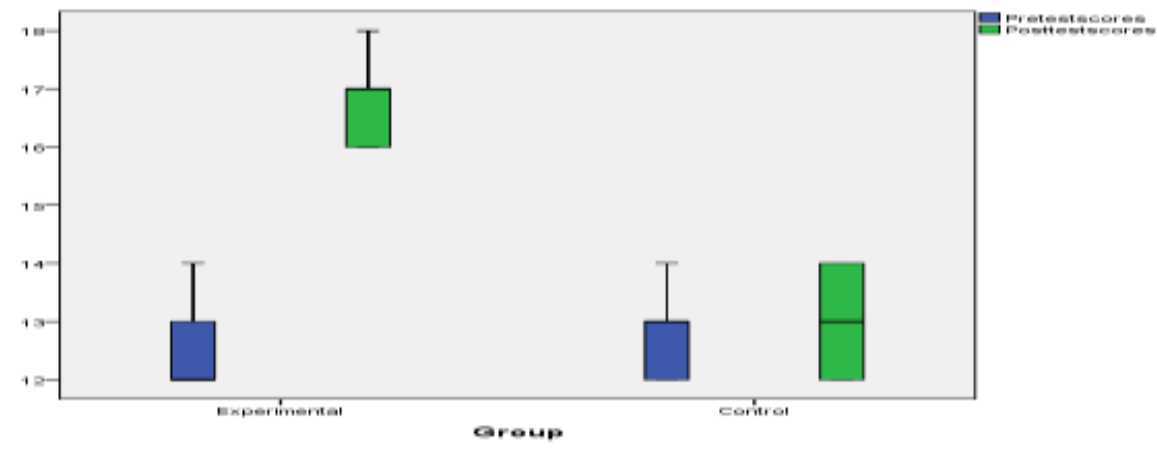




\subsection{Inferential statistics}

Before embarking on the analysis of the statistical analysis, let us examine the data sets to see if they adhere to the assumptions of the independent t-test, namely the normality of the data and equal variances. Looking at the data numerically in Table3, there is no normal distribution in the pre-test, and post-test since the $\mathrm{p}$-value is less than the pre-defined significance level.

Table3: Tests of Normality

Tests of Normality

\begin{tabular}{|ll|r|r|r|r|r|r|}
\hline & \multicolumn{3}{|c|}{ Kolmogorov-Smirnov $^{\text {a }}$} & \multicolumn{3}{c|}{ Shapiro-Wilk } \\
\cline { 2 - 8 } & Group & Statistic & \multicolumn{1}{c|}{ df } & \multicolumn{1}{c|}{ Sig. } & \multicolumn{1}{c|}{ Statistic } & \multicolumn{1}{c|}{ df } & \multicolumn{1}{c|}{ Sig. } \\
\hline Pretestscores & Experimental &, 330 & 30 &, 000 &, 745 & 30 &, 000 \\
& Control &, 209 & 30 &, 002 &, 835 & 30 &, 000 \\
\hline Posttestscores & Experimental &, 273 & 30 &, 000 &, 785 & 30 &, 000 \\
& Control &, 259 & 30 &, 000 &, 774 & 30 &, 000 \\
\hline
\end{tabular}

Wilcox (2003) advanced that tests of normality often suffer from low power to detect violations, and thus we cannot be certain that the data is normally distributed, just by looking at the numerical results of the tests. Instead, researchers should study graphics as well (Wilkinson, 1999). Graphs can be in the form of histograms, normal Q-Q plots, and boxplots.

According to Table4, the assumption of homogeneity of variances is met, since the p-value is greater than the pre-defined significance level.

Table4: Leven's Test for Equality of Variances

\begin{tabular}{|c|c|c|}
\hline & \multicolumn{2}{|c|}{ Equality of Variances } \\
\hline & $\mathrm{F}$ & Sig. \\
\hline $\begin{array}{ll}\text { Pretest scores Equal } \\
\text { variances assumed }\end{array}$ & .194 & .662 \\
\hline $\begin{array}{l}\text { Posttest scores Equal } \\
\text { variances not assumed }\end{array}$ & 1.208 & .276 \\
\hline
\end{tabular}

\section{Independent sample t-test}

In order to see if the results of this study were statistically significant, an Independent T-test was conducted on the data. The preliminary description of the data indicated that the experimental group outscored the control group in the posttest without being subject to any inferences (the control group: $M=13.06, S d=.868, N=30$ and the experimental group: $M=16.73, S d=.739$, $\mathrm{N}=30$ ). The analysis of the Independent T-test confirmed that there were statistically significant differences between the performance of both groups in the posttest. With a $\mathrm{t}=17.606, \mathrm{df}=58, \mathrm{P}=.000$ and $95 \% \mathrm{Cl}=3.249,4.083$, we can confidently reject the null hypothesis which says that there is no difference between the experimental group and the control group on the ground of instructional games. In principle, the observed patterns in Table5 below appear in a consistent and meaningful way. Based on the table below, one can be $95 \%$ confident that the differences are, by no means, the effect of the treatment given to the experimental group. Most significantly is the positive response in favour of the research hypothesis the current study attempts to test. In this respect, we reject the null hypothesis and conclude that the experimental group outperformed the control group in the post-test.

\begin{tabular}{|c|c|c|c|c|c|c|c|c|c|c|}
\hline \multicolumn{11}{|c|}{ Independent Sample Itest } \\
\hline & & \multicolumn{2}{|c|}{$\begin{array}{l}\text { Levene's Test for Equaliny of } \\
\text { Variantes }\end{array}$} & \multicolumn{7}{|c|}{ Ftestfor Equality of Means } \\
\hline & & \multirow[b]{2}{*}{$\mathrm{F}$} & \multirow[b]{2}{*}{ Sig. } & \multirow[b]{2}{*}{$\mathrm{t}$} & \multirow[b]{2}{*}{ df } & \multirow[b]{2}{*}{ Sig (2-taled) } & \multirow{2}{*}{$\begin{array}{l}\text { Nean } \\
\text { Diference }\end{array}$} & \multirow{2}{*}{$\begin{array}{l}\text { Std Emor } \\
\text { Dfferense }\end{array}$} & \multicolumn{2}{|c|}{$\begin{array}{l}\text { 95\% Confidence intenal of the } \\
\text { Diference }\end{array}$} \\
\hline & & & & & & & & & Lower & Usper \\
\hline Prefestscores & $\begin{array}{l}\text { Equal varianozs } \\
\text { assumed }\end{array}$ & \multirow[t]{2}{*}{194} & \multirow[t]{2}{*}{662} & $-1,535$ & \multirow[b]{2}{*}{57,940} & .130 & \multirow{2}{*}{$\begin{array}{l}-29167 \\
-29167\end{array}$} & \multirow{2}{*}{$\begin{array}{l}19001 \\
.19001\end{array}$} & \multirow{2}{*}{$\begin{array}{l}-, 67201 \\
-, 67202\end{array}$} & \multirow{2}{*}{$\begin{array}{l}08868 \\
\square 8869\end{array}$} \\
\hline & $\begin{array}{l}\text { Equal variances not } \\
\text { assumed }\end{array}$ & & & $-1,535$ & & .130 & & & & \\
\hline \multirow[t]{2}{*}{ Postlestscures } & $\begin{array}{l}\text { Equal variantes } \\
\text { assumed }\end{array}$ & \multirow[t]{2}{*}{1,208} & \multirow[t]{2}{*}{.276} & 17,606 & \multirow{2}{*}{$\begin{array}{r}5 B \\
56,570\end{array}$} & \multirow[t]{2}{*}{.000} & \multirow{2}{*}{$\begin{array}{r}3,66667 \\
3,66667\end{array}$} & \multirow{2}{*}{$\begin{array}{r}.20826 \\
.20826\end{array}$} & \multirow{2}{*}{$\begin{array}{l}3,24979 \\
3,24957\end{array}$} & \multirow{2}{*}{$\begin{array}{l}4,08354 \\
4,08377\end{array}$} \\
\hline & $\begin{array}{l}\text { Equal variances not } \\
\text { assumed }\end{array}$ & & & 17,606 & & & & & & \\
\hline
\end{tabular}

Table5: The Independent Sample T-test 
This section is concerned with the analysis and discussion of the findings.

Hypothesis1: The experimental group will outscore the control group in the immediate post-test.

In line with the findings of Bullard and Anderson (2014), it was predicted that the experimental group would score higher than the control group in the posttest. The difference was theorized to be due to the treatment, instructional games, they received during the training. Nevertheless, the control group was anticipated to perform less than the experimental group if the treatment had been a success.

A brief look at (Table2) reveals that the experimental group outperformed the control group as anticipated (with a gain score of 4.64). At the descriptive level, the comparison made between the two groups indicated that they vary in their mean performance. Being unable to determine, in conclusive terms, the significance of the observed differences, the T-test was run on the data sets. Therefore, the Independent T-test further uncovered the degree of significance (Table5), which confirms, by all means, that the experimental group outscored the control group in the posttest. In brief, the participants who received instruction using the tictac toe and board games scored higher than those in the control group who studied the present simple and present continuous traditionally. Thus, the momentous difference between both groups can be justified on the ground of the treatment given to the experimental group during the training. The alternative hypothesis is confirmed, indicating that instructional games had a positive effect on students' understanding of grammar. This suggests that a causal relationship does, in fact, exist between the independent variable (instructional games) and the dependent variable (grammar), at least $95 \%$, as it is the convention in social sciences and humanities.

Hypothesis2: There will be no difference between the experimental group and the control group based on instructional games

The second hypothesis argued that the training would have no effect on students' understanding of the present simple and present continuous. However, test results allow an affirmative response to the second hypothesis, in the sense that subjects in the experimental group continued to perform significantly better than those in the control group. This indicates that the treatment given to the experimental group was so efficient that it improved their comprehension of the present simple and the present continuous. The null hypothesis is, therefore, rejected. The findings obtained support the work of Bullard $\&$ Anderson (2014) on the effect of instructional games on teaching grammar and, in particular, the impact of tic-tac toe and board game on students' understanding of the present continuous and the present simple. In this regard, students who experienced the instructional games training enhanced their understanding of grammar from pre-test to post-test, compared to participants in the control group who received no treatment. The results advocate, to a large extent, the assumption that instructional games have a momentous effect on students' overall grammar comprehension, enabling them to know, use, and internalize grammar rules.

\subsection{Analysis of the feedback questionnaire}

Notwithstanding this paper subscribes to the quantitative paradigm, to the extent that the nature of the data collected can only be measured statistically, the subjects' responses in the feedback questionnaire provide further support for the findings of this study. Before embarking on the analysis, it is vital to remind the reader that the feedback questionnaire was only administered to the experimental group at the end of the training. The questionnaire helped us to collect qualitative data. The latter was used as an instrument to interpret the quantitative data and assess the subjects' overall impression concerning the training. Accordingly, the analysis of the subjects' responses from the experimental group revealed that most participants expressed their positive attitudes towards the training. Participants' answers to the feedback questionnaire seemed to be in line with the findings of the study.

\section{Conclusion}

This paper has examined the effects of tic-tac toe and board game on the present simple and the present continuous. The findings showed that subjects were equal at the outset of the training. However, the experimental group outperformed the control group in the post test.

\subsection{Pedagogical implications}

The revealing results of the study seem to suggest some pedagogical implications. First, instructional games might become a useful tool for teachers in an EFL context to facilitate students' grammar comprehension and encourage their autonomy and creativity. Second, teachers would better encourage students to assume the responsibility for their own learning, gradually decreasing their provision of support and assistance, use of prompt feedback, and modelling. Additionally, since the participants demonstrated a good level of autonomy after the treatment, it is indicative that instructional games are effective in the sense that they empower the learners to assume responsibility for their own learning. 


\subsection{Limitations}

The quasi-experimental design has generally got many limitations, and thus this study is not an exception. The limitations identified in this paper are no random selection, small sample, and time constraints. Because of these limitations, our findings could not be generalized, and hence they are open to discussions. However, since the design adopted is similar to classroom reality, we believe the results obtained from this study might be safely applied to any Moroccan common core classroom.

Acknowledgments: This study would not have been accomplished without the support, encouragement and collaboration of the instructors and common core students who took part in this study.

\section{References}

[1] Anderson, C. A., Shibuya, A., Ihori, N., Swing, E. L., Bushman, B. J., Sakamoto, A., \& Saleem, M. (2010). Violent video game effects on aggression, empathy, and prosocial behavior in Eastern and Western countries: A meta-analytic review. Psychological Bulletin, 136, 151173. doi:10.1037/a0018251

[2] Alemi, M. (2010). Educational games as a vehicle to teaching vocabulary. The Modern Journal of Applied Linguistics 174, $2240-2256$.

[3] Bullard, S.B., \& Anderson, N. (2014). "I'll take commas for €200" An instructional Intervention using games to help students master grammar skills. Journalism \& Mass Communication Educator 69 (1), 5-16.

[4] Donmus, V. (2010). The use of social networks in educational computer-game based foreign language learning. Procedia-Social and Behavioral Sciences 9, 1497-1503.

[5] Ferguson, C. J. (2013). Violent video games and the Supreme Court. American Psychologist, 68, 57-74. doi:10.1037/a0030597

[6] Gee, J. P. (2007). Good video games+ good learning: Collected essays on video games, learning and literacy. Peter Lang.

[7] Granic, I., Lobel, A., \& Engels, R. C. M. E. (2013). The benefits of playing video games. Developmental Psychopathology Department, Behavioural Science Institute, Radboud University Nijmegen, Montesso \& rilaan 3, 6525.

[8] Hainey, T., Westera, W., Connolly, T.M., Royle, L., Baxter, G., \& Beeby, R.B. (2013). Students' attitudes toward playing games and using games in education: Comparing Scotland and the Netherlands. Computers \& Education 69, 474-484.

[9] Lemola, S., Brand, S., Vogler, N., Perkinson-Gloor, N., Allemand, M., \& Grob, A. (2011). Habitual computer game playing at night is related to depressive symptoms. Personality and Individual Differences, 51, 117- 122. doi: 10.1016/j.paid.2011.03.024

[10] Michael, D. R., \& Chen, S. L. (2005). Serious games: Games that educate, train, and inform. Muska \& Lipman/Premier-Trade.

[11] Miller, M. \& Hegelheimer, V. (2006). The SIMs meet ESL incorporating authentic computer simulation games into the language classroom. Interactive Technology and Smart Education 4, 311-328.

[12] Moller, I., \& Krahé, B. (2009). Exposure to violent video games and aggression in German adolescents: A longitudinal analysis. Department of Psychology, University of Potsdam, Potsdam, Germany. Volume 35, 75-89.

[13] Paris, T. N. S. T., \& Yussof, R. L. (2012). Enhancing grammar using board game. Elsevier Ltd, 12, 213-221.

[14] Pratchett, R. (2005). Gamers in the UK: Digital play, digital lifestyles, BBC Creative Research and Development: 1-25.

[15] Prensky, M. (2001). Digital game-based learning. New York: McGraw-Hill.

[16] Richards, J. C., \& Schmitt, R. (2010). Longman dictionary of language teaching and applied linguistics (4th edition). London: Pearson Education Limited.

[17] Squire, K.D. (2007). Games, learning and society: Building a field. Educational Technology, 51-55.

[18] Vernon, S. (2006). Teaching grammar with fun learning games. Retrieved from http://symplyesl.com/articles/97/1/Teaching-GrammarwthFun-Learning Games/Page1.html

[19] Warriner, J. (2008). Grammar. Usage. Mechanics. Sentences. New York: Holt, Rinehart and Winston.

[20] Wilcox, R.R. (2003). Applying contemporary statistical techniques. San Diego, CA: Elsevier Science.

[21] Wilkinson, L., \& Task Force on Statistical Inference, APA, Science Directorate (1999). Statistical methods in psychology journals: Guidelines and explanations. American Psychologist, 54 (8). 594-604. 